\title{
Article
}

\section{Measures of PHV and the effect on directional dynamic stability to identify risk factors for injury in elite football}

Rhodes, David, Alexander, Jill, Jeffrey, Josh, Birdsall, Daniel and Maden-Wilkinson, Joe

Available at https://clok.uclan.ac.uk/31794/

Rhodes, David orcid iconORCID: 0000-0002-4224-1959, Alexander, Jill orcid iconORCID: 0000-0002-6492-1621, Jeffrey, Josh, Birdsall, Daniel and MadenWilkinson, Joe (2020) Measures of PHV and the effect on directional dynamic stability to identify risk factors for injury in elite football. The Journal of Sports Medicine and Physical Fitness. ISSN 0022-4707

It is advisable to refer to the publisher's version if you intend to cite from the work. 10.23736/50022-4707.20.10352-9

For more information about UCLan's research in this area go to http://www.uclan.ac.uk/researchgroups/ and search for <name of research Group>.

For information about Research generally at UCLan please go to http://www.uclan.ac.uk/research/

All outputs in CLoK are protected by Intellectual Property Rights law, including Copyright law. Copyright, IPR and Moral Rights for the works on this site are retained by the individual authors and/or other copyright owners. Terms and conditions for use of this material are defined in the policies page. 
Measures of phv and the effect on directional dynamic stability to identify risk factors for injury in elite football

David RHODES ${ }^{1}$, Jill ALEXANDER ${ }^{2 *}$, Josh JEFFREY ${ }^{3}$, Daniel BIRDSALL ${ }^{2}$, Joe MADENWILKINSON ${ }^{3}$.

${ }^{1}$ Institute of Coaching and Performance, School of Sport and Health Sciences, University of Central Lancashire, Preston, UK; ${ }^{2}$ Sport, Nutrition and Clinical Sciences, School of Sport and Health Sciences, University of Central Lancashire, Preston, UK; ${ }^{3}$ Everton Football Club, Finch Farm Training Complex, Finch Lane, Halewood, Liverpool, UK.

\section{*Corresponding Author}

Jill Alexander

Sport, Nutrition and Clinical Sciences, School of Sport and Health Sciences, University of Central Lancashire, Brook Building, Preston, UK, PR1 2HE.

E-mail: JAlexander3@uclan.ac.uk 


\begin{abstract}
BACKGROUND: To analyse the relationship between Peak Height Velocity (PHV) and Dynamic Balance (Y-Balance) vs non-peak growth to identify risk factors for non-contact lower limb injuries using a retrospective study design in elite youth footballers.

METHODS: Ninety-Three elite category 1 academy football players completed Y-Balance assessment during the preseason screening assessment. Data in relation to Y-Balance and Peak Height Velocity measures was than analysed retrospectively and correlated against injury audit data to identify relationships between the variables.
\end{abstract}

RESULTS: A significant correlation was identified between Peak Height Velocity (PHV) and measures of directional dynamic stability utilising Y-Balance assessment $(\mathrm{p} \leq 0.001)$. No significant correlations were identified between PHV and injury or injury and dynamic stability scores $(p>0.05)$. Injury occurrence for players within predicted periods of PHV was represented as $45 \%$, within the cohort contained within the study.

CONCLUSIONS: Evidently periods of growth and maturation within elite academy footballers has a detrimental effect on directional dynamic stability performance. However, caution must be taken with interpreting the significance of this relationship and the effect it has on injury occurrence. Consideration must be given to quantifying key aetiological factors associated with injury during adolescence and refrain from reliance on measures of PHV.

\title{
KEY WORDS
}

Risk Factors - Soccer - Adolescent - Performance 


\section{Introduction}

Injury occurrence during periods of rapid growth results in considerable time-loss in sports such as football. Recent evidence highlights 5.6 injuries per $1000 \mathrm{hrs}$ of training and match play, with an increased incidence of non-contact ankle injuries $>19 \%$ highlighted in players aged 13.5-14.5 years in academy football ${ }^{1}$. This potentially indicates a relationship exists between injury prevalence and maturation ${ }^{2-4}$. Peak height velocity (PHV) refers to a period of accelerated growth ${ }^{5}$ and may help explain the increase in injury incidence, through changes in mechanically stiffer muscle-tendon unit and a decrease in flexibility with maturation ${ }^{6,7}$.

Identification of modifiable risk factors for injury through screening is necessary to optimise development and performance outcomes in youth football. To date, there is a paucity of evidenced based literature identifying risk factors for injury within elite youth athletes. The substantial incidence and severity of non-contact lower limb injuries sustained within football at academy level warrants research to identify modifiable risk factors ${ }^{8,9}$. Dynamic balance is defined as the ability to perform tasks while maintaining stable positions ${ }^{10}$, of which is influenced by an array of factors including sensory information, joint range of motion, and strength ${ }^{11,12}$. It is also a key aetiological factor associated with sustaining non-contact lower limb injury when performing football specific actions ${ }^{8,13,14}$. Previous research has demonstrated that by improving neuromuscular control and subsequently improving dynamic stability injury risk may be reduced ${ }^{15}$. The loss of dynamic stability during increased rates of growth has the potential to alter gait mechanics and increase peak ground reaction force on landing and has consistently shown to be a marker of future injury risk for the lower limb ${ }^{16}$. Predominantly, research is often within adult populations however, and therefore does not address potential aetiological risk factors associated with periods of peak growth in adolescents ${ }^{9,17-19}$.

Research has demonstrated the use of the Y-Balance Test (YBT) to quantify dynamic stability in elite sporting populations ${ }^{14}$. Whilst considered as an appropriate functional assessment due to its speed, portability, consistency, efficiency, and objectivity ${ }^{20-23}$, performance of the YBT requires a plethora of physical qualities, including strength, flexibility, and neuromuscular control to maintain equilibrium ${ }^{22,24}$. It is proposed that dynamic balance may be affected during adolescent maturation, thus potentially 
diminishing performance, and heightening injury risk. Although the underlying mechanisms remain unclear $^{10,22}$. It is suggested however that this rapid change in limb length in relation to changes of centre of mass (COM), during periods of peak growth, may be attributed to changes within dynamic stability. The aim of the current study is to analyse the relationship between Peak Height Velocity (PHV) and Dynamic Balance (YBT) in elite academy footballers. Retrospective data analysis will also determine if dynamic balance performance is a risk factor for non-contact lower limb injuries in this specific population.

\section{Methods}

\section{Participants}

Retrospective data from the 2018-2019 competitive football season, for ninety-three male elite category 1 academy football players (mean PHV $13.79 \pm 0.5$, height $170.7 \pm 11.75 \mathrm{~cm}$, sitting height $95.2 \pm 3.2 \mathrm{~cm}$ and weight $59.4 \pm 13.07 \mathrm{~kg}$ ) completed the present study. All participants provided written informed consent in accordance with Department and Faculty Research Ethics committees at the host University, and in accordance with the Helsinki Declaration. Players who were free from injury in the 6 months leading up to predicted peak height were included in the study to consider the standard error measurement in maturation status ${ }^{5}$. All players were in full training and playing in competitive fixtures for the club throughout the 2018-2019 season.

\section{Experimental Design}

Players PHV data was calculated utilising the Mirwald method ${ }^{5}$. To enable the appropriate calculation to be made players measures of height, weight, body mass, stature, and sitting height were completed. Height measures were taken utilising a fixed stadiometer to the nearest $0.1 \mathrm{~cm}$ and weight was recorded with a Seca Beam Balance (Welwyn Garden City, UK) to the nearest $0.1 \mathrm{~kg}$. Injury risk identification protocols within the academy incorporate regular measures of dynamic stability during predicted periods of PHV throughout the playing season. To quantify dynamic stability the YBT protocol was utilised and throughout windows of PHV. 
Non-contact lower limb player injury data was determined over the subsequent 4 weeks post their dynamic stability measure and taken within 1 week of entering their predicted PHV. This window of data collection reduced proprioceptive training effect, as research has shown that stability training must be completed for a minimum of $4-6$ weeks to display improvements ${ }^{29}$. For the purposes of the present study, injury is defined as a non-contact lower limb causing $>3$ days loss of training/performance.

\section{Protocol}

Within the present study, dynamic stability scores were observed where players were within 1 week of entering periods of PHV over the competitive season (2018-2019). Dynamic stability data was collected at the clubs training ground and all experimental measures were completed between 13:00 and 17:00 hrs to account for the effects of circadian rhythm and in accordance with regular competition times $^{25}$. Data capture for dynamic stability negated potential learning effects ${ }^{26}$, as players completed previous trials of the YBT leading up to entering PHV periods. During collection of dynamic stability via YBT measures, participants were asked to remove their shoes and socks to eliminate any stability provided by their footwear ${ }^{27}$, prior to completing stability testing on both lower limbs. Once stood single leg on the centre plate participants were asked to push the reach indicator block with the contralateral limb in the anterior (Ant), posterior-medial (PM) and posterolateral (PL) directions simultaneously. Each participant maintained a single leg stance with their hands on the pelvis whilst pushing the reach indicator as far as possible in each of the directions listed. Participants were asked to produce one successful complete trial for the YBT, demonstrating the method above. A complete trial was classified as invalid if the participant did not return to the start position, failed to maintain a unipodal stance on the platform, kicked the reach indicator block to gain more distance, stepped on top of the reach indicator for support or removed their hands from their hips. The mean distance in each direction on the right and left sides were utilised for data analysis. Previous research has demonstrated the YBT to have excellent inter and intra-rater reliability with ICC reported at $0.85^{28}$. 


\section{Data Analysis}

Participants completed three repetitions on the YBT. YBT scores in each direction (Ant, PM and PL) were normalised for lower limb length to calculate maximum distance (\%MAXD) utilising the following equation excursion distance/limb length $\times 100=\%$ MAXD. This accounted for potential differences in leg lengths amongst individuals ${ }^{30}$. Mean distance in each direction on the right and left sides were utilised for data analysis. Injury data was displayed graphically to represent injuries sustained within periods of predicted PHV for all players.

\section{Statistical Analysis}

Pearson's correlation coefficients quantified the linear relationship between YBT and PHV. All statistical analysis was completed using PASW Statistics Editor 25.0 for windows (SPSS Inc, Chicago, USA). Statistical significance was set at $P \leq 0.05$. Coefficient of correlation (r) and respective level of significance ( $\mathrm{p}$ value) describes total variance. The following criteria quantified magnitude of the correlation $<0.1$, trivial; $>0.1$ to 0.3 , small; $>0.3$ to 0.5 , moderate; $>0.5$ to 0.7 , large; $>0.7$ to 0.9 , very large; and $>0$ to 1.0 , almost perfect.

\section{Results}

Table I summarises the mean data and standard deviations observed for PHV and YBT scores for all players. The percentage of lower limb non-contact musculoskeletal injuries sustained by players within this period of PHV was observed. It was identified that 42 players within their predicted PHV (45\%), sustained a non-contact lower limb musculoskeletal injury within 4 weeks of their PHV test in this period (Figure 1).

Table i: Displaying Mean and Standard Deviations for Stability Scores (YBT -cm), PHV (years) and Maturity Offset (years). 


\begin{tabular}{|c|c|c|c|c|c|c|c|c|}
\hline & Ant (R) & Ant (L) & PM (R) & PM (L) & PL (R) & PL (L) & $\begin{array}{l}\text { Age at } \\
\text { PHV }\end{array}$ & $\begin{array}{c}\text { Maturity } \\
\text { Offset** }\end{array}$ \\
\hline Mean & $56.39 \pm 6.64$ & $57.00 \pm 5.90$ & $104.75 \pm 9.56$ & $106.08 \pm 8.23$ & $107.55 \pm 9.98$ & $108.65 \pm 10.10$ & $13.79 \pm 0.50$ & $1.96 \pm 0.99$ \\
\hline
\end{tabular}

* Maturity offset $=$

$-9.236+[0.0002708 \times$ leg length and sitting height interaction $]$

- [0.001663 x age and leg length interaction]

$+[0.007216 \mathrm{x}$ age and sitting height interaction $]$

$+[0.02292 \mathrm{x}$ weight by height ratio $]$

\section{***Insert Figure 1 here $* * *$}

Statistically significant correlation coefficients were displayed for all directional dynamic stability scores and predicted PHV ((R) ant $r=0.62, p \leq 0.001$; (L) Ant $r=0.63, p \leq 0.001$; (R) PM $r=0.48$, $p \leq 0.001$; (L) PM $r=0.62, p \leq 0.001$; (R) PL $r=0.50, p \leq 0.001$; (L) PL $r=0.43, p \leq 0.001$ ). No significant correlation coefficients were displayed for all dynamic stability scores and injury occurrence ((R) ant $r=0.09, p=0.43$; (L) Ant $r=0.10, p=0.36$; (R) PM $r=-0.03, p=0.80$; (L) PM $r=0.12$, $p=0.28$; (R) PL $r=-0.21, p=0.85$; (L) PL $r=-0.03, p=0.77$ ). Correlation coefficients between injury and PHV also identified no significance $(r=0.07, p=0.43)$ (Table ii). 
Table ii: Displaying Relationships between Stability Parameters and PHV and Injury for Elite Academy Footballers.

\begin{tabular}{|c|c|c|c|c|c|c|c|}
\hline & (R) Ant & (L) Ant & (R) PM & (L) PM & (R) PL & (L) PL & \multirow{2}{*}{ PHV } \\
\hline & Stability & Stability & Stability & Stability & Stability & Stability & \\
\hline \multirow[t]{4}{*}{ PHV } & $r=0.62, p \leq$ & $r=0.63, p \leq$ & $r=0.48, p \leq$ & $r=0.62, p \leq$ & $r=0.50, p \leq$ & $r=0.43, p \leq$ & \\
\hline & $0.001^{+}$ & $0.001^{\dagger}$ & $0.001^{\prime}$ & $0.001^{\dagger}$ & $0.001^{\dagger}$, & $0.001^{\dagger}$ & \\
\hline & $C I=54.30-$ & $C I=55.07-$ & $C I=101.95$ & $C I=103.60_{-}$ & $C I=104.66-$ & $C I=105.75-$ & \\
\hline & 56.77 & 57.21 & 105.83 & 106.85 & 108.72 & 109.84 & \\
\hline \multirow[t]{4}{*}{ Injury } & $r=0.09, p=$ & $r=0.10, p=$ & $r=-0.03, p=$ & $r=0.12, p=$ & $r=-0.21, p=$ & $r=-0.03, p=$ & $r=0.07, p$ \\
\hline & 0.43 & 0.36 & 0.80 & 0.28 & 0.85 & 0.77 & $=0.43$ \\
\hline & $C I=54.49$ & $C I=55.26-$ & $C I=102.20-$ & $C I=103.84-$ & $C I=104.91-$ & $C I=105.99$ & $C I=-.04-$ \\
\hline & 57.38 & 57.82 & 106.39 & 107.41 & 109.27 & 110.41 & .83 \\
\hline
\end{tabular}

$\dagger$ denotes significance at 0.01 level

* denotes significance 0.05 level

Confidence Intervals at $95 \%$ 


\section{Discussion}

The aim of the present study was to examine the relationships that exist between PHV, dynamic stability and injury within an elite category 1 Premier League Academy squad. Current results demonstrated that $45 \%$ of players eligible for the study sustained a non-contact lower limb musculoskeletal injury within 4 weeks of their PHV period of testing. Previous research has indicated that within periods of peak growth young players are more susceptible to injury ${ }^{2,4}$ and this has been attributed to mechanically stiffer muscle-tendon units and reductions in flexibility ${ }^{6,7}$. Research has been limited in relation to the effect of this reduced mechanical function and dynamic stability, although the consensus suggests it is a key contributory aetiological factor associated with sustaining non-contact lower limb injury $8,13,14$. Although no correlations were demonstrated between players that sustained an injury and predicted PHV, dynamic stability scores from the current investigation indicated significant correlations between all directional dynamic stability scores and predicted PHV.

The data observed in the present study eliminated the period of error pre and post predicted PHV, to determine exact injury occurrence within the immediate period of PHV. Results from the present study highlight significant small to moderate correlations between PHV and dynamic stability scores. Suggesting that during periods of predicted PHV, changes are visible within dynamic stabilisation. Potentially, supporting the notion of adolescent awkwardness, whereby kinetic asymmetries exist across dynamic balance performance parameters ${ }^{32}$. The strength of these correlations highlight some key considerations in relation to the utilisation of PHV to modify training or utilisation as an indication of injury risk. Due to the error associated with these estimations the findings potentially show us that players in predicted PHV, were not actually in PHV and future studies should observe measures 6 months pre and post predicted PHV. It also emphasises the importance of practitioners not being reliant on PHV measures, alternatively developing a battery of tests associated with the MOI's of common non-contact injuries sustained in academy footballers ${ }^{1}$. The knowledge gained from the current study helps ensure that practitioners take into account frequent measures that consider maturity offset and predicted $\mathrm{PHV}^{5}$. 
Findings from the present study identified no significant correlations between players sustaining injury and predicted PHV or injury and dynamic stability scores. Although, statistical significance was not indicated it would be problematic as a practitioner to ignore a $45 \%$ injury occurrence rate of adolescents within periods of predicted peak growth. Again, the importance of the measure of predicted PHV and the accuracy of it is debatable ${ }^{31}$. Posing the question is it more important to consider changes in measures associated with key aetiological risk factors and changes within these during adolescence, rather than trying to identify windows like PHV? The mean age of predicted growth in the present study highlighted was $13.79 \pm 0.5$ years, supporting the theory of maturity offset proposed by Mirwald et al $(2002)^{5}$. There is no doubt that mechanical and anatomical function is influenced negatively by $\mathrm{PHV}^{6,7}$. Earlier research has suggested that increased ground reaction forces on landing and gait mechanics could be associated with changes in dynamic stability during periods of peak growth ${ }^{16}$. Maturity offset and PHV however, present large windows where the training and development of players from a coaching perspective could be significantly affected with the potential to inhibit player development. Consistently, research has shown us that adolescents within the age range of $13-15$ experience PHV and this age range has been associated with increased injury occurrence ${ }^{1,4,17,18}$. Findings from the current study highlight a key window to increase observations of player function and applying appropriate interventions. Future research should focus on intervention studies to determine the effect of specific training approaches on the detrimental effects of growth on function, rather than the emphasis on a specific age of development and adapting training based on this.

Academy injury audits have previously highlighted the occurrence of non-contact lower limb injury ${ }^{1}$ being suggestive of potential causes. PHV allows practitioners to estimate or closely observe periods of peak growth where players have been shown to be at an increased risk of sustaining injury ${ }^{3,4}$. Issues associated with PHV measures and maturity offset discussed by Mirwald et al (2002) $)^{5}$, highlight a maturation period error of \pm 6 months $^{31}$. The authors acknowledge this in the current study findings and agree that adaptations of training often occur within these predicted periods with a view to reducing injury risk. This potential highlights a large window where players could lose training time, vital to their development. This window represents a contemporary debate for practitioners working within 
elite academy football, as to when to adapt training load or apply intervention strategies in the hope of reducing injury risk.

The current study observed that injury incidence remains high for players within PHV and suggestive that PHV has a detrimental effect on dynamic stability performance. Understanding injury risk and factors that influence these are of significant interest to applied practitioners to optimise injury prevention and performance outcomes. The ever-growing physical demands of youth football and the considerable time and development loss due to injury or adaptation of training warrants the investigation between growth and maturation and those factors closely associated with injury incidence ${ }^{1,9,18,19}$. These findings emphasise that the monitoring of dynamic stability in academy footballers during adolescence is important, and is a key contributory factor to non-contact injury ${ }^{2,4}$. The YBT therefore has merit in an applied setting not only to identify those athletes of a heightened risk of injury, but also to identify existing asymmetries relative to each player during periods of growth. The implementation of continuous monitoring and targeted interventions would proactively assess individuals in order to decrease injury incidence ${ }^{4,14,31}$.

This research identifies practical methods commonly utilised in an applied setting for injury screening in players during periods of maturation. Reliable and valid measures are needed to inform current and applied practice due to the significant incidence, re-injury risk and implications on youth athletes ${ }^{1,14,19}$. Identifying risk factors for injury with sensitive measures to detect meaningful changes that can be implemented within an applied setting have significant merit ${ }^{8}$. It is important to note however, that stability measures represent one factor associated with sustaining non-contact lower limb injury. Therefore, its significance in isolation must be interpreted with caution. The aetiology of injuries is multifactorial ${ }^{8}$ therefore identifying correlations between injury and risk factors will enable more effective management and rationale behind injury prevention measures tailored to individuals during growth phases. Currently there is a lack of evidence-based literature regarding risk factors for injury within elite paediatric athletes. The current study highlights those factors associated with injury risk and their relationship to growth and maturation. Understanding injury risk and factors that influence 
these are of interest to improve applied research and practice optimising injury prevention and development outcomes.

\section{Conclusion}

Dynamic stability is a key aetiological factor associated with sustaining non-contact lower limb injury. Evidently, from the current study findings, detrimental changes in dynamic stability are associated with periods of $\mathrm{PHV}$, but these cannot be attributed solely to injury occurrence in this predicted period. Considerations therefore to the accuracy of PHV as a measure and the error identified via calculations of maturity offset should be of importance. This potentially presents a 12 month window where PHV would occur, however identifying when PHV actual occurs within this window is difficult. The development of a battery of measures, informed by mechanics of injury commonly associated with lower limb injuries, should be considered to inform practice. Dynamic stability is one factor affected by maturation and regular measures during adolescence should be quantified to identify potential injury risk associated with detrimental changes in this measure. Practitioners should become more reliant on determining risk factors and developing measures to quantify these risk factors to inform adaptations to training in adolescents. Caution should be taken however with the use of PHV as an injury predictor independently.

\section{References}

1. Renshaw A, Goodwin PC. Injury incidence in a premier league youth soccer academy using the consensus statement: a prospective cohort study. Br Med J Open Sport Ex Med. 2016;26:16.

2. Di Fiori JP, Benjamin HJ, Brenner JS, Gregory A, Jayanthi N, Landry GL, Luke A. Overuse injuries and burnout in youth sports: a position statement from the American Medical Society for Sports Medicine. Br J Sports Med. 2014;48:287-288. 
3. Malina RM, Bouchard C, Bar-Or O. Timing and sequence of changes during adolescence. In: Growth, Maturation and Physical Activity. Champaign, IL: Human Kinetics. 2004;307-333.

4. Van der Sluis A, Elferink-Gemser MT, Coelho-e-Sliva MJ, Nijboer JA, Brink MS, Visscher C. Sports injuries aligned to peak height velocity in talented pubertal soccer players. Int J Sports Med. 2014;35:351-355.

5. Mirwald RL, Baxter-Jones ADG, Bailey DA, Beunen GP. An assessment of maturity from anthropometric measurements. Med Sci Sports Ex. 2002;34:689-694.

6. Philippaerts RM, Vaeyens R, Janssens M, van Renterghem B, Matthys D, Craen R, Bourgois J, Vrijens J, Beunen G, Malina RM. The relationship between peak height velocity and physical performance in youth soccer players. J Sports Sci. 2006;24:221-230.

7. Ford KR, Myer GD, Hewett TE. Longitudinal effects of maturation on lower extremity joint stiffness in adolescent athletes. Am J Sports Med 2010;38:1829-1837.

8. Ekstrand J. Epidemiology of football injuries. Sci Sports 2008;23:73-77.

9. Rumpf M, Cronin J. Injury incidence, body site and severity in soccer players aged 6-18 years: Implications for injury prevention. Strength Conditioning J. 2012;34:20-31.

10. Ricotti L. Static and dynamic balance in young athletes. J Human Sport Ex. 2011;6:616-628.

11. Grigg P. Peripheral neural mechanisms in proprioception. J Sports Rehab. 1994;3:2-17.

12. Palmieri RM, Ingersoll CD, Stone MB, Krause AB. Center-of-pressure parameters used in the assessment of postural control. J Sports Rehab. 2002;11:51-66.

13. Arnason A, Sigurdsson SB, Gudmundsson A, Holme I, Engebretsen 1, Bahr R. Risk factors for injuries in football. Am J Sports Med. 2004;32:5-16.

14. Read P, Oliver J, De Ste Croix M, Myer G, Lloyd R. The effects of maturation on measures of asymmetry during neuromuscular control tests in elite male youth soccer players. Paediat Ex Sci 2018;30:168-175.

15. Dallinga JM, Benjaminse A, Lemmink KAPM. Which screening tools can predict injury to the lower extremities in team sports? A systematic review. Sports Med. 2012;42:791-815.

16. Malliaras P, Cook JL, Kent P. Reduced ankle dorsiflexion range may increase the risk of patella tendon injury among volleyball players. J Sci Med Sport. 2006;9:304-309. 
17. Price RJ, Hawkins RD, Hulse MA. The Football Association and medical research programme: an audit of injuries in academy youth football. Br J Sports Med. 2004;38:466-471.

18. Cloke D, Spencer S, Hodson A. The epidemiology of ankle injuries occurring in English Football Association academies. Br J Sports Med. 2009;43:1119-1125.

19. Read P, Oliver J, De Ste Croix M, Myer G, Lloyd R. Injury risk factors in male youth soccer players. Strength Cond J. 2015;37:1-7.

20. Plisky PJ, Gorman PP, Butler RJ, Kiesel KB, Underwood FB, Elkins B. The reliability of an instrumented device for measuring components of the star excursion balance test. North Am J Sports Phys Ther. 2009;4:92-99.

21. Butler RJ, Southers C, Gorman PP, Kiesel KB, Plisky PJ. Differences in soccer players' dynamic balance across levels of competition. J Athl Train. 2012;47:616-620.

22. Gribble PA, Hertel J, Plisky PJ. Using the star excursion balance test to assess dynamic postural-control deficits and outcomes in lower extremity injury: A literature and systematic review. J Athl Train. 2012;47:339-357.

23. Gribble PA, Kelly SE, Refshauge KM, Hiller CE. Interrater reliability of the star excursion balance test. J Athl Train. 2013;48:621-626.

24. Gonell AC, Romero JAP, Soler LM. Relationship between the y-balance test scores and soft tissue injury incidence in a soccer team. Int J Sports Phys Ther. 2015;10:955-966.

25. Sedliak M, Haverinen M, Hakkinen K. Muscle Strength, Resting Muscle Tone and EMG Activation in Untrained Men: Interaction Effect of time of Day and Test Order-Related Confounding Factors. J Sports Med Phys Fitness. 2011;51:560-570.

26. Hinman M. Factors Affecting Reliability of the Biodex Balance System: A summary of Four Studies. J Sport Rehab. 2000;9:240-252.

27. Dong-Kyu L, Gyoung-Mo K, Sung-Min H, Jae-Seop O. Correlation of the Y-Balance Test with Lower limb Strength of the Adult Woman. J Phys Ther Sci. 2014;26:641-643.

28. Smith LJ, Creps JR, Bean R, et al. Performance and Reliability of the Y Balance Test in High School Athletes. J Sports Med Phys Fit. 2017;58:1671-1675. 
29. Gioftsidou A, Malliou P, Pafis G, Beneka A, Tsapralis K, Sofokleous P, Kouli O, Roka S, Godolias G. Balance Training Programs for Soccer Injuries Prevention. J Human Sport Ex. 2012;7:639-647.

30. Robinson R, Gribble P. Kinematic predictors of performance on the star excursion balance test. J Sport Rehab. 2008;17:347-357.

31. Koziel SM, Malina RM. Modified Maturity Offset Prediction Equations: Validation in Independent Longitudinal Samples of Boys and Girls. Sports Med. 2018;48:221-236.

32. Read P, Oliver J, De Ste Croix M, Myer G, Lloyd R. Hopping and landing performance in male youth soccer players: effects of age and maturation. Int J Sports Med. 2017;38:902-908. 